\title{
LA JURISDICCIÓN UNIVERSAL DE PROTECCIÓN DE DERECHOS FUNDAMENTALES EN LA JURISPRUDENCIA CHILENA (COMENTARIO al fallo de la Corte Suprema Rol N 17.393-2015) Universal Jurisdiction for the Protection of Fundamental Human Rights in Chilean Case Law (A Commentary of the Supreme Court Ruling Number 17.393-2015)
}

\section{Javier Gallego Saade}

Universidad Adolfo Ibáñez, Chile

Abogado, Universidad de Chile. Profesor de Derecho Público y Ética Profesional (UAI). Profesor de Derecho Penal Internacional (U. de Chile, UAI). javier.gallego@uai.cl.

\section{Juan Francisco Lobo}

Universidad Adolfo Ibáñez, Chile

Abogado, Universidad de Chile. Profesor de Derecho Penal Internacional (U. de Chile, UAI), Derechos Humanos y Teoría del Derecho (UDP) y Derecho Internacional Público (UAI). jflobo@ug.uchile.cl.

\section{RESUMEN}

La Corte Suprema, en su fallo de 18 de noviembre de 2015, Rol No 17.393-2015, ha resuelto requerir al gobierno de Chile (materialmente a la Cancillería) que solicite a la Comisión de Derechos Humanos de la Organización de Estados Americanos que se constituya en Caracas, Venezuela, de modo de constatar el estado de salud y privación de libertad de Leopoldo López y Daniel Ceballos, identificados en el fallo como prisioneros políticos. El fundamento de dicho requerimiento es el deber de protección de los derechos fundamentales a la vida, igualdad, privacidad, de petición y de asociación, consagrados en el artículo 19 de la Constitución chilena, números 1, 2, 4, 14 y 15, respectivamente. La Corte ha entendido que el deber de protección de derechos fundamentales que la Constitución le impone al Estado de Chile la habilita para extender la vigencia de las normas que consagran esos derechos extraterritorialmente. Ha llamado a este ejercicio "jurisdicción universal de protección de derechos humanos". Este artículo evalúa esta práctica desde las perspectivas del derecho constitucional (I), derecho internacional (II) y derecho penal (III). La tesis del artículo es que la Corte en cada una de estas dimensiones incurre en confusiones y errores dogmáticos importantes.

\section{Palabras clave}

Recurso de protección; derechos constitucionales; derechos humanos; jurisdicción universal; comunidad internacional.

\section{Abstract}

The Chilean Supreme Court, in its ruling 17.393-2015 of 18 November 2015, resolved that the Chilean Government (specifically, the Chancery) should demand that the Inter-American Commission of Human Rights meet in Caracas, Venezuela, in order to ascertain the health status 
Javier Gallego Saade y Juan Francisco Lobo

La jurisdicción universal de protección de derechos fundamentales en la jurisprudencia chilena (comentario al fallo de la Corte Suprema Rol N¹7.393-2015)

and the conditions of the arrest of Leopoldo López and Daniel Ceballos, identified in the ruling as political prisoners. The motive behind such a request is the obligation to protect the fundamental right to life, equality, privacy, petition, and freedom of association, established in Article 19 of the Chilean Constitution -numbers 1, 2, 4, 14 and 15, respectively. The Court considered that the obligation to protect fundamental rights imposed on the Chilean State by the Constitution allowed it to extend the validity of the norms that establish such rights extraterritorially. The Court called this power 'Universal Jurisdiction for the Protection of Fundamental Human Rights'. This paper evaluates this decision from the perspective of constitutional (I), international (II), and criminal law (III). The thesis of this paper is that the Court runs into confusion and makes serious dogmatic mistakes in each of these areas.

\section{KEY WORDS}

Appeal for legal protection; constitutional rights; human rights; international jurisdiction; international community.

\section{DeRechos Constitucionales y DEREChOS HUMANOS}

El fallo de la Corte Suprema (la Corte) que aquí se comenta revoca en segunda instancia la decisión de la Corte de Apelaciones de Valparaíso, frente a esta se dedujo un recurso de protección en favor de los ciudadanos venezolanos. El estado de riesgo que legitima, desde la perspectiva de los recurrentes, la acción constitucional de protección es la huelga de hambre que llevan adelante dichos ciudadanos y el peligro para la vida que su prolongación implica. La Corte reconoce que el principal objeto de la medida cautelar de requerimiento dirigida a la Comisión de Derechos Humanos de la OEA es la protección de la vida, pues "el resto de los derechos que se insinúan amagados, aparecen solamente como ilustrativos" (considerando cuarto). Respecto de ese derecho a la vida, la Corte constata su reconocimiento "en todos los ordenamientos jurídicos del mundo", y su configuración como norma tanto en el artículo 19 N 1 de la Constitución chilena como en la Declaración Universal de Derechos Humanos.

Sin embargo, es en torno a esta diferencia, entre derechos constitucionales y derechos humanos, que el razonamiento de la Corte se vuelve errático, y a ratos incomprensible. Así, para efectos de legitimar un ejercicio de jurisdicción de protección de derechos constitucionales que se pretende tenga efectos fuera del territorio nacional, la Corte considera primero la pretensión de los requirentes, fundada en el hecho de que la regulación de la acción de protección (en sus requisitos de legitimación en el artículo 20 de la Constitución, y en lo procedimental en un auto acordado, varias veces reformado) no distingue, o más bien, no especifica, ni la persona ni el lugar en el que se produce el acto u omisión lesivo de derechos, para efectos de su legitimación activa (considerando primero). La Corte hace suyo este razonamiento en el considerando noveno, e insiste que ni el artículo $19 \mathrm{~N}^{\mathrm{o}} 1 \mathrm{ni}$ el artículo 20 de la Constitución distinguen nacionalidad o ubicación geográfica para efectos de dispensar protección constitucional a la vida.

Ahora bien, sin perjuicio de esto, la Corte intenta justificar su decisión disponiendo del factor de conexión "personalidad pasiva" (una conexión de pertenencia al Estado que ejerce jurisdicción de protección por parte de los afectados por un acto que lesiona sus derechos fundamentales). La regulación que contiene el auto acordado en cuestión distribuye competencia entre Cortes de Apelaciones en razón del territorio en que se comete el acto o se incurre en la omisión lesiva del derecho. Se ha entendido que en caso 
de diferir el domicilio del titular del derecho lesionado y el lugar en que se produce el hecho lesivo, la competencia recae en la Corte de Apelaciones respectiva del primero ${ }^{1}$. El razonamiento de la Corte extiende el criterio de admisibilidad de la acción, pues declara que los jueces chilenos son competentes para conocer de un hecho lesivo del derecho a la vida en Venezuela, porque los efectos del mismo alcanzan a ciudadanos chilenos, de modo que el domicilio de los afectados, en este sentido, determina la Corte de Apelaciones competente. Los recurrentes sostienen que la huelga de hambre que tiene lugar en Venezuela "les afecta personal y directamente"; argumento que la Corte acoge, pues concluye, en este considerando, que "la Corte de Apelaciones de Valparaíso resulta competente para conocer territorialmente de ese asunto".

Si es el caso que la competencia de la Corte de Apelaciones de Valparaíso queda determinada territorialmente en razón de que a ciudadanos chilenos les afecta "personal y directamente" que en Venezuela se realice una huelga de hambre con riesgo para la vida, la Corte debiera hacer explícito que el fundamento de su decisión es la protección de la integridad psíquica (como manifestación del derecho a la vida) de personas ubicadas en Chile, y no el reforzamiento del derecho a la vida de ciudadanos venezolanos. Si la Corte entiende que la jurisdicción de protección no necesita factor de conexión, demostrar que la Corte de Apelaciones es competente en razón del territorio resulta innecesario.

Es cierto que el recurso de protección ha sido instrumentalizado por la jurisprudencia chilena al punto de transformarlo en un mecanismo de control jurisdiccional de actos de la administración, a falta de una vía específica para ello ${ }^{2}$, pero nunca antes se había extendido este uso al control de actos de la administración central de un Estado no sometido a la Constitución chilena. La razón es obvia: disponer de mecanismos de reforzamiento de derechos fundamentales domésticos para elevar un reclamo por el desconocimiento de esos derechos por otro Estado es innecesario. La comunidad latinoamericana dispone de su propio arreglo para dicho procedimiento, la Convención Americana de Derechos Humanos. Este tratado configura, en su artículo 45, un procedimiento de comunicaciones dirigidas a la Comisión, que permite a los Estados parte reclamar lesiones a los derechos humanos por parte de otros Estados, y ventilar un procedimiento (artículos 48-50) cuyo desarrollo es condición previa para que intervenga en el asunto la Corte Interamericana (artículo 61.2). La competencia de la Comisión ha sido reconocida (en virtud de lo que señala el artículo 45.1) tanto por Chile como por Venezuela ${ }^{3}$.

1 Ríos, Lautaro (2007). "La Acción Constitucional de Protección en el Ordenamiento Jurídico Chileno". Estudios Constitucionales 5(2): 58.

2 Ferrada, Juan Carlos, Andrés Bordalí y Kamel Cazor (2003). "El recurso de protección como mecanismo de control jurisdiccional ordinario de los actos administrativos: una respuesta inapropiada a un problema jurídico complejo". Revista de Derecho XIV: 67-81.

3 Chile lo hizo al momento de la ratificación, el 8 de octubre de 1990. Venezuela, por su parte, la reconoció en una declaración de 24 de junio de 1981. Se debe hacer presente en todo caso que Venezuela denunció el sistema continental de derechos humanos, en virtud de lo que dispone el artículo 78 de la Convención. Acerca de esta denuncia en detalle véase OchoA, María Julia (2014). "La protección de los derechos humanos en Venezuela frente a la denuncia de la Convención Americana sobre Derechos Humanos". Revista Latinoamericana de Derechos Humanos 25(1): 195-211. Agradecemos a los editores del Anuario por hacernos notar este punto. 
Javier Gallego Saade y Juan Francisco Lobo

La jurisdicción universal de protección de derechos fundamentales en la jurisprudencia chilena (comentario al fallo de la Corte Suprema Rol N¹7.393-2015)

Por cierto, disponer de dicho procedimiento le corresponde al Poder Ejecutivo, no a los tribunales. La Corte desconoce no solo este principio básico de distribución de competencias, sino también el rol de los derechos humanos en el derecho doméstico. En efecto, invoca en el considerando tercero la Convención Americana, y declara que la vigencia de los derechos humanos que este y otros tratados consagran solo es posible "si se autoriza y [...] se obliga a los Estados a su cabal ejercicio a través de sus tribunales nacionales". Es cierto que la Corte Interamericana de Derechos Humanos (Corte IDH) ha declarado que los tribunales de los Estados están no solo autorizados, sino obligados a disponer de la Convención como premisa de sus decisiones. Desde el célebre fallo AlmonacidArellano v. Chile 4 , se ha denominado a esta práctica "control de convencionalidad"5, y ha permitido, según la doctrina especializada, un cambio de paradigma, desde una lógica subsidiaria (en la relación entre la Convención y el derecho doméstico de los Estados parte) a una de integración, es decir, de pleno reconocimiento de las normas de derechos humanos en el derecho doméstico, y asentamiento de la Convención como norma de superior jerarquía ${ }^{6}$. Pero la Corte IDH nunca ha interpretado esta práctica como una facultad de los jueces para elevar requerimientos a otros Estados parte. Al contrario, la ha restringido al "marco de [las] respectivas competencias y regulaciones procesales" del Poder Judicial7, materializada en una revisión de adecuación de "disposiciones legales domésticas", frente al derecho de la Convención ${ }^{8}$.

De esta manera, la Corte desconoce la diferencia estructural entre derechos constitucionales y derechos humanos ${ }^{9}$. En este sentido, resulta incomprensible que en uno de los considerandos del fallo (considerando octavo) se suscriba la tesis del rango supraconstitucional de las normas de derecho internacional de derechos humanos, para argumentar en el considerando inmediatamente siguiente (considerando noveno) que la justificación externa de la decisión apela al derecho a la vida del artículo $19 \mathrm{n}^{\circ} 1$ de la Constitución. Un razonamiento que parece confuso, o propio de un estado de indecisión, puede explicarse más bien como una instrumentalización de la categoría de los derechos constitucionales, con la excusa de inventar una nueva forma de jurisdicción de protección de los derechos humanos, que hace enteramente dispensable el sistema convencional de derechos humanos de la Convención Americana. En esta invención la Corte se ha servido de la autoridad de una práctica mucho más asentada en el ejercicio de jurisdicción punitiva estatal: la jurisdicción universal.

4 Corte IDH. Caso Almonacid Arellano y otros vs. Chile (excepciones preliminares, fondo, reparaciones y costas). Sentencia de 26 de septiembre de 2006. Serie C N 154.

5 Dulitzky, Ariel (2015). "An Inter-American Constitutional Court? The Invention of the Conventionality Control by the Inter-American Court of Human Rights”. Texas International Law Journal 50(1): 45-93.

6 Dulitzky, 2015: 52 ss.

7 Conte IDH. Caso Trabajadores Cesados del Congreso (Aguado Alfaro y otros) vs. Perú (excepciones preliminares, fondo, reparaciones y costas). Sentencia de 24 de noviembre de 2006. Serie C N 158 , párr. 128; caso Gelman vs. Uruguay (fondo y reparaciones). Sentencia de 24 de febrero de 2011. Serie C N²21, párr. 193; caso Atala Riffo y Niñas vs. Chile (excepciones preliminares, fondo, reparaciones y costas). Sentencia de 24 de febrero de 2012. Serie C N²39, párr. 282.

8 Conte IDH. Caso Cabrera García y Montiel Flores vs. México (excepciones preliminares, fondo, reparaciones y costas). Sentencia de 26 de noviembre de 2010. Serie C N²20, párr. 225.

9 Fundamental al respecto, Gardbaum, Stephen (2008). "Human Rights as International Constitutional Rights". European Journal of International Law 19(4): 749-768. 


\section{LA JURISDICCIÓN UNIVERSAL EN EL DERECHO INTERNACIONAL}

El concepto de jurisdicción envuelve las potestades que posee un Estado para prescribir normas, adjudicarlas y hacerlas cumplir ${ }^{10}$. La jurisdicción universal, que corresponde a uno de los títulos de que disponen los Estados para ejercer extraterritorialmente su jus puniendi, consiste en una especie de jurisdicción criminal en virtud de la cual un Estado está facultado para conocer hechos respecto de los cuales no existe ningún factor de conexión, como territorialidad, personalidad activa, pasiva o protección de intereses nacionales ${ }^{11}$.

Se trata de una jurisdicción basada exclusivamente en la naturaleza del crimen cometido $^{12}$, la que ha sido caracterizada como una verdadera actio popularis ejercida por un Estado en el concierto internacional ${ }^{13}$. Históricamente, la jurisdicción universal ha sido reservada por las naciones para el enjuiciamiento de los piratas en tanto hoste humani generis ${ }^{14}$.

Este tipo de jurisdicción se clasifica en "absoluta" o "condicionada", dependiendo de si se exige la presencia del acusado en el territorio del Estado persecutor (condicionada) o si se puede aplicar en contra de una persona ubicada en cualquier lugar del mundo (absoluta $)^{15}$. El tipo más común en la práctica de los Estados corresponde a la jurisdicción universal condicionada ${ }^{16}$.

Ahora bien, en el fallo en comento la Corte incurre en varios errores en relación con el concepto y con la correcta aplicación de la jurisdicción universal como institución del derecho internacional. El principal de ellos se refiere a las fuentes normativas de la jurisdicción universal, mientras que los otros dicen relación con su naturaleza y su práctica.

\section{Fuentes internacionales de la jurisdicción universal}

$\mathrm{El}$ considerando tercero del fallo señala tres fuentes normativas internacionales desde las que emanaría supuestamente la facultad de dicha magistratura de ejercer la jurisdicción universal para proteger los derechos humanos de ciudadanos extranjeros: (i) los tratados internacionales; (ii) la costumbre internacional; y (iii) las normas de jus cogens.

10 Bassiouni, M. Cherif (2001). "Universal Jurisdiction for International Crimes: Historical Perspectives and Contemporary Practice". Virginia Journal of International Law 42(1): 89.

11 Brownlie, Ian (2012). Principles of Public International Law. Edited by James Crawford. $8^{\text {th }}$ Edition. Oxford: Oxford University Press, pp. 687-688.

12 Macedo, Stephen (ed.) (2001). The Princeton Principles on Universal Jurisdiction. Princeton: Princeton University, Principle 1, p. 28.

13 Bassiouni, 2001: 88

14 Bassiouni, 2001: 108-112.

15 Cassese, Antonio et al. (2013). International Criminal Law. 3rd Edition. Oxford: Oxford University Press, p. 278.

16 Werle, Gerhard (2014). Principles of International Criminal Law, 3rd Edition. Oxford: Oxford University Press, p. 78. 
Javier Gallego Saade y Juan Francisco Lobo

La jurisdicción universal de protección de derechos fundamentales en la jurisprudencia chilena (comentario al fallo de la Corte Suprema Rol N¹7.393-2015)

La Corte admite que los tratados invocados en su considerando tercero no contemplan "taxativamente" la jurisdicción universal, pero soslaya este hecho excusándose en la adhesión universal de la que gozan los derechos humanos.

En realidad, tres de los tratados citados por la Corte no regulan en absoluto la jurisdicción universal, sino que establecen disposiciones referidas a jurisdicción territorial ${ }^{17}$ o internacional ${ }^{18}$. De los demás tratados mencionados, uno regula la jurisdicción universal "condicionada", con cláusula alternativa aut dedere aut judicare ${ }^{19}$. Únicamente los Convenios de Ginebra de 1949 y su Protocolo Adicional I de 1977, citados por la Corte, establecen una jurisdicción universal obligatoria y sin condiciones expresas ${ }^{20}$ de territorialidad para los Estados partes ${ }^{21}$.

En definitiva, tan solo los tratados internacionales referidos a los delitos de tortura y crímenes de guerra regularían expresamente la posibilidad, e incluso el deber para los Estados, de ejercer la jurisdicción universal. No obstante, en el recurso a favor de los prisioneros políticos venezolanos no se denuncia ni la comisión de tortura ni de crímenes de guerra en su contra, por lo que mal podrían aplicarse dichos instrumentos internacionales.

En cuanto a la costumbre internacional, la Corte no aporta antecedentes que permitan acreditar la existencia de una norma consuetudinaria que justifique el ejercicio de jurisdicción universal para dispensar protección constitucional, sino que se limita a señalar en el considerando tercero algunos de los criterios fijados por los tratadistas para la procedencia de esta jurisdicción, a saber, (i) la subsidiariedad del tribunal que ejerce jurisdicción universal respecto del tribunal con competencia territorial originaria; (ii) que la jurisdicción emane de una fuente idónea del derecho internacional; y (iii) que la legislación nacional aplicable no sea contraria al derecho internacional.

La doctrina especializada ha denominado a estos estándares como "criterios de razonabilidad", los que constituyen un umbral que es necesario sobrepasar para justificar la injerencia de un sistema jurisdiccional en el ámbito de otro. En tal sentido, Ximena Fuentes ha indicado los siguientes criterios de razonabilidad para justificar dicha intromisión: (i) la existencia de consenso internacional acerca del ejercicio del jus puniendi para ciertos tipos de hechos; (ii) la razonabilidad de las penas prescritas; (iii) la preeminencia del Estado territorial por sobre el que pretende ejercer jurisdicción universal por encontrarse en mejor posición para administrar justicia; (iv) la persecución de un interés legítimo reconocido así por la comunidad internacional; (v) el

17 Organización de las Naciones Unidas. Convención para la Prevención y Sanción del Delito de Genocidio, adoptada el 9 de diciembre de 1948, art. 6.

18 Estatuto de Roma de la Corte Penal Internacional. Adoptado el 17 de junio de 1998, art. 1; OrGanización de los Estados Americanos. Convención Americana de Derechos Humanos, adoptada el 22 de noviembre de 1969, art. 33

19 Organización de las Naciones Unidas. Convención contra la Tortura y Otros Tratos Crueles, Inhumanos y Degradantes, adoptada el 10 de diciembre de 1984, art. 6.

20 No obstante, Cassese considera que la mejor interpretación consiste en exigir la presencia del acusado en el territorio del Estado persecutor. Véase CASSESE et al. (2013): 287.

21 Organización de las Naciones Unidas. Convenios de Ginebra I, II, III y IV, adoptados el 12 de agosto de 1949, CGI, art. 49; CGII, art. 50; CGIII, art. 129; CGIV, art. 146; y Protocolo Adicional I a los Convenios de Ginebra, adoptado el 10 de junio de 1977 , art. 85 . 
cumplimiento de las disposiciones de debido proceso; (vi) el respeto por las instituciones de la inmunidad estatal y (vi) por la integridad territorial de los demás Estados. Solo respetando todos estos criterios se podrá defender la libertad de los Estados de ejercer jurisdicción universal ${ }^{22}$, considerando que de acuerdo con la opinión separada de los jueces de la Corte Internacional de Justicia (CIJ) Higgins, Kooijmans y Buergenthal en el caso Arrest Warrant, "la legislación nacional y la jurisprudencia -esto es, la práctica estatal- es neutral en cuanto al ejercicio de la jurisdicción universal"23.

Por último, por lo que se refiere al jus cogens, este es definido, en el considerando tercero del fallo, como una norma imperativa de derecho internacional general, en los términos de la Convención de Viena de 1969, es decir, como "una norma aceptada y reconocida por la comunidad de Estados en su conjunto como norma que no admite acuerdo en contrario y que solo puede ser modificada por una norma ulterior de derecho internacional general que tenga el mismo carácter"24.

Es importante señalar que las normas de jus cogens operan en el derecho internacional a la manera de disposiciones de orden público indisponibles para los Estados en sus relaciones convencionales ${ }^{25}$. La Corte Internacional de Justicia ha indicado como ejemplo de tales normas indisponibles la prohibición del uso de la fuerza ${ }^{26}$ y del genocidio ${ }^{27}$.

Sin embargo, de la existencia de tales normas no se sigue eo ipso la facultad de ejercer jurisdicción universal, como lo demuestra el caso de la prohibición del uso de la fuerza, cuyo correlato punitivo, el crimen de agresión, no da todavía lugar a la jurisdicción universal en la práctica internacional ${ }^{28}$.

\section{Naturaleza de la jurisdicción universal}

En adición al fracaso de la Corte por identificar las fuentes formales del derecho internacional de las cuales supuestamente emanaría su potestad para ejercer el tipo de jurisdicción invocado, el máximo tribunal comete un segundo error manifiesto al desnaturalizar la jurisdicción universal y extendiéndola más allá de materias criminales, en particular, aplicándola a la tutela constitucional de derechos fundamentales.

En efecto, la Corte contraviene incluso la opinión de Gonzalo Aguilar por ella misma citada en su considerando octavo, autor que al reflexionar respecto de la jurisdicción

22 Fuentes, Ximena (2004). “La Jurisdicción Universal y la Corte Penal Internacional”. Revista de Estudios de la Justicia 4: 129-130.

23 CIJ. República Democrática del Congo v. Bélgica (Arrest Warrant). Fondo. Opinión separada de los jueces Higgins, Kooijmans y Buergenthal, de 14 de febrero de 2002, Serie 837, párr. 45.

24 Organización de las Naciones Unidas. Convención de Viena sobre el Derecho de los Tratados, adoptada el 23 de mayo de 1969, art. 53.

25 Gómez, Antonio (2003). El Ius Cogens Internacional. Estudio histórico-crítico. México D.F.: UNAM, p. 88.

26 CIJ. Nicaragua v. Estados Unidos (Actividades Militares y Paramilitares en y contra Nicaragua). Fondo. Sentencia de 27 de junio de 1986. Serie 520, párr. 190

27 CIJ. República Democrática del Congo v. Ruanda. Fondo. Sentencia de 3 de febrero de 2006. Serie 126 , párr. 64.

28 Werle, 2014: 76. Villarino, Cristina (2006). "The Crime of Aggression before the House of Lords". Journal of International Criminal Justice 4: 866-877. 
Javier Gallego Saade y Juan Francisco Lobo

La jurisdicción universal de protección de derechos fundamentales en la jurisprudencia chilena (comentario al fallo de la Corte Suprema Rol N¹7.393-2015)

universal remarca que "es necesario insistir en que esta última denominación se utiliza en relación con el ejercicio de la jurisdicción penal" 29.

De este modo, la Corte deliberadamente se aleja del consenso doctrinario existente en torno a la naturaleza exclusivamente penal de la jurisdicción universal, como fue plasmado en el documento autoritativo generado por un panel de expertos acerca del tema, quienes invitados por la Universidad de Princeton produjeron los "Principios de Princeton sobre la Jurisdicción Universal” en 2001. De conformidad con el principio número 1.1, "la jurisdicción universal es jurisdicción penal basada únicamente en la naturaleza del delito", dando lugar a su ejercicio solamente crímenes graves tales como la piratería, la esclavitud, los crímenes de guerra, los crímenes contra la paz, los crímenes de lesa humanidad, el genocidio y la tortura (principio 2.1) ${ }^{30}$. A ellos Bassiouni agrega el crimen de apartheid ${ }^{31}$.

Para algunos autores, los delitos que justificarían el ejercicio de la jurisdicción universal deberían limitarse aún más, reduciéndose a los crímenes de guerra, el genocidio y la tortura ${ }^{32}$, a los cuales los jueces Higgins, Kooijmans y Buergenthal de la Corte Internacional de Justicia añaden la piratería ${ }^{33}$.

La Corte, por el contrario, asegura en su considerando sexto que la jurisdicción universal se ha expandido hacia el derecho privado, incluyendo el derecho de familia y comercial, sin proporcionar mayores antecedentes para demostrar su aserto. Todavía más, la Corte omite toda mención a la norma comparada arquetípica para el ejercicio civil de la jurisdicción universal, la Alien Tort Claims Act (ATCA) de Estados Unidos ${ }^{34}$.

De conformidad con dicha norma, los tribunales federales norteamericanos "tendrán jurisdicción original para conocer cualquier acción civil ejercida por un extranjero a causa exclusivamente de un ilícito extracontractual (tort), cometido en infracción al derecho de las naciones o a un tratado de los Estados Unidos"35. Instaurada en el siglo XVIII para resguardar los derechos de agentes diplomáticos, la ATCA fue remozada en 1980 en el caso Filártiga v. Peña-Irala, en que un ciudadano paraguayo obtuvo en Estado Unidos la indemnización de perjuicios por la tortura cometida por otro ciudadano paraguayo en Paraguay. En adelante, se han conocido reclamaciones análogas por crímenes de lesa humanidad, de guerra y genocidio ${ }^{36}$. Sin embargo, se ha tratado de pretensiones orientadas a perseguir responsabilidades pecuniarias, y en ningún caso la jurisdicción universal civil fundada en la ATCA se ha extendido a la tutela de derechos constitucionales en los Estados Unidos, atendido que solamente habilita para conocer causas entre extranjeros ante sus tribunales.

29 Aguilar, Gonzalo (2006). "El Principio de Jurisdicción Universal: Una Propuesta de Aplicación en Chile". Estudios Constitucionales 4(1): 341.

30 Macedo, 2001: 28-29.

31 Bassiouni, 2001: 108.

32 Werle, 2014: 75; Fuentes, 2004: 130.

33 CIJ. República Democrática del Congo v. Bélgica (Arrest Warrant). Opinión separada, párrs. 60-62.

34 Higgins, Rosalyn (2010). Problems and Process. International Law and How We Use it. Oxford: Clarendon Press, p. 58; Corte Internacional de Justicia. República Democrática del Congo v. Bélgica (Arrest Warrant). Opinión separada, párr. 48.

35 U.S.C. $\S 1350$

36 Murphy, Sean (2012). Principles of International Law. $2^{\text {nd }}$ Edition. Michigan: Thomson Reuters, pp. 260-262. 


\section{Práctica de la jurisdicción universal}

Por último, no habiendo identificado correctamente las fuentes de la jurisdicción universal y habiendo desnaturalizado su concepto doctrinario, la Corte describe erróneamente la práctica de este tipo de jurisdicción al indicar en su considerando séptimo como ejemplo de la misma el caso de Augusto Pinochet, detenido y procesado ante los tribunales británicos entre 1998 y 1999.

Según Bassiouni, el caso Pinochet fue en realidad motivado por el ejercicio de jurisdicción penal extraterritorial por España a base del criterio de la personalidad pasiva, ante esto el Reino Unido se vio enfrentado al dilema jurisdiccional aut dedere aut judicare ${ }^{37}$, optando por la primera de las opciones.

Si bien es cierto que el caso Pinochet confirió breve momentum a la doctrina de la jurisdicción universal a fines del siglo XX, lo cierto es que nuestra Corte Suprema convenientemente omite mencionar el episodio más conspicuo del fracaso de dicha institución por exceso de celo político, esto es, el caso de Bélgica. Dicho país ejerció una agresiva política de jurisdicción universal desde 1999, la que fue abruptamente frenada en 2002 por la Corte Internacional de Justicia en Arrest Warrant, y sobre todo, por la presión política de Estados Unidos en $2003^{38}$.

\section{Derechos fundamentales y DeRecho PENaL}

¿Por qué la Corte incurre en estos errores al invocar la práctica de la jurisdicción universal? Una respuesta posible es que no conoce la regulación internacional al respecto ni ha puesto suficiente atención a su ejercicio en el derecho comparado. Una revisión de este material, como se acaba de mostrar, es suficiente para constatar que se trata de una práctica históricamente reservada al ejercicio de punición, y no de protección (de derechos fundamentales).

Existe, por cierto, otra manera de responder esa pregunta. Para atenderla es necesario volver a los instrumentos normativos internacionales citados por la Corte. Como ya se hizo notar, la Corte cita primordialmente tratados punitivos, esto es, cuerpos de normas que configuran estándares de comportamiento y establecen sanciones para reforzar su cumplimiento. La Corte admite que estos tratados no regulan taxativamente el ejercicio de jurisdicción universal, pero postula que ello es irrelevante pues los derechos humanos gozan de validez universal. Más arriba ya se hizo notar que algunos de estos tratados no regulan en absoluto la práctica. Uno de estos es el Estatuto de Roma que establece la Corte Penal Internacional. Resulta esclarecedor para efectos de comprender la función que la Corte le asigna a este tratado, el hecho que lo presente (junto con otros tratados punitivos) junto a la Convención Americana, en el mismo considerando tercero, como antecedentes a favor de la adhesión universal a los derechos humanos, y en consecuencia como respaldo a la invención de una jurisdicción universal de protección de derechos fundamentales.

\footnotetext{
37 Bassiouni, 2001: 125.

38 Langer, Máximo (2011). "The diplomacy of universal jurisdiction: The political branches and the transnational prosecution of international crimes". American Journal of International Law 105(1): 26-32.
} 
Javier Gallego Saade y Juan Francisco Lobo

La jurisdicción universal de protección de derechos fundamentales en la jurisprudencia chilena (comentario al fallo de la Corte Suprema Rol N¹7.393-2015)

Esto evidencia no ya solo la falta de comprensión de la posición de la jurisdicción universal en el derecho internacional, sino también que para la Corte no hay ninguna diferencia relevante entre las normas de la Convención Americana y las normas del Estatuto de Roma. Para la Corte, ambos tratados regulan la misma institución: derechos humanos.

En este punto nuestra Corte no está sola. Al inicio de este artículo se hacía referencia a la diferencia estructural entre derechos constitucionales y derechos humanos: es decir, entre derechos fundamentales frente al Estado y derechos fundamentales frente a la comunidad universal. El surgimiento del derecho internacional de derechos humanos, y de sus diversos mecanismos institucionales de consagración y adjudicación, hizo necesaria la diferenciación estructural. El mismo derecho internacional de derechos humanos, sin embargo, ha contribuido a deshacer la distinción crucial entre normas punitivas y normas de derechos fundamentales, al punto que actualmente no es inusual que en la literatura especializada el derecho penal internacional se presente como un subsistema del derecho internacional de derechos humanos ${ }^{39}$, antes que como la proyección internacional del derecho penal estatal.

Esta conflación estructural la ha identificado nítidamente Darryl Robinson, quien es escéptico frente al discurso que asume que las normas penales deben ser coextensivas con normas de derechos humanos o derecho humanitario. Robinson sostiene que no reparar en las diferencias de estructura y fines de estas áreas del derecho conlleva a omitir o descuidar principios legitimatorios del ejercicio de castigo penal ${ }^{40}$. El autor presenta esta tensión intrínseca como una "crisis de identidad", y se la imputa al derecho penal internacional, al menos en la forma en que lo presenta el discurso más generalizado.

Por cierto, más allá de la crisis de identidad, existe una relación importante entre el derecho penal internacional y los derechos humanos: una relación que admite una reconstrucción dogmática sensible a principios liberales de legitimación del ius puniendi. En primer lugar, puede ser el caso que el principio legitimatorio de protección de bienes jurídicos adquiera una estructura propia en la dimensión internacional. Así, puede ser que para el derecho internacional, los derechos humanos individuales sean el objeto de protección que legitima el derecho penal internacional ${ }^{41}$, así como en la historia de la categoría del bien jurídico los derechos subjetivos alguna vez ocuparon ese lugar ${ }^{42}$.

39 Véase Smeulers, Alette y Fred Grünfeld (2011). International Crimes and other Gross Human Rights Violations. Leiden and Boston: Martinus Nijhoff Publishers, pp. 14 y ss. Por lo demás, nuestro Tribunal Constitucional, al someter a control de constitucionalidad el Estatuto de Roma, se dedicó a desarrollar la discusión en torno a la correcta interpretación del inciso segundo del art. $5^{\circ}$ de la Constitución, implícitamente asignándole al Estatuto la condición de tratado de derechos humanos. TRibunal Constitucional Chileno. Fallo Rol 346. 8 de abril de 2002: cons. $59^{\circ}$ a $73^{\circ}$.

40 Robinson, Darryl (2008). "The identity crisis of International Criminal Law". Leiden Journal of International Law 21: 929.

41 Véase, por ejemplo, Ambos, Kai (2013). Derecho Penal y Procesal Penal Internacional y Europeo. Nuevos Ensayos. Santiago: Legal Publishing, Thomson Reuters. También SAfferling, Christoph (2004) “Can Criminal Prosecutions be the Answer to Massive Human Rights Violations?". German Law Journal 5(12): 1474 ("A primera vista parece natural que, inspirada en el funcionamiento del sistema de derecho penal en el nivel nacional, la comunidad internacional decida revestir sus bienes más valiosos bajo una forma similar de protección, de este modo dando origen al derecho penal en el nivel internacional”).

42 Schünemann, Bernd (2007). "El principio de protección de bienes jurídicos como punto de fuga de los límites constitucionales de los tipos penales y de su interpretación”, en La Teoría del Bien Jurídico (editor: Hefendehl, Ronald), Madrid: Marcial Pons, pp. 203 y ss. 
Ahora bien, ello es especialmente problemático en este caso considerando las referencias del Preámbulo del Estatuto de Roma (el instrumento autoritativo del derecho penal internacional convencional) a "la paz, la seguridad y el bienestar de la humanidad"; identificados como intereses protegidos por dicho sistema. La doctrina tempranamente notó la correspondencia de intereses entre la Carta de las Naciones Unidas y este Preámbulo, al menos en lo que respecta al reforzamiento de la paz y la seguridad ${ }^{43}$.

De este modo, solo el objeto "humanidad" puede proveer un fundamento independiente a la punición de crímenes internacionales. Esto trae aparejada una enorme carga de reconstrucción dogmática en torno a este concepto, para efectos de diferenciarlo de los derechos humanos individuales, e identificar el objeto lesionado con el quebrantamiento de normas punitivas internacionales. Las estrategias disponibles para asumir este desafío son variadas, desde su categorización como bien jurídico colectivo (asumiendo un concepto material de humanidad, como agregación de individuos de la especie humana), hasta la asunción del rol simbólico del concepto, que opera como expresión del desarrollo individual de acciones o actitudes humanas ${ }^{44}$. Como estrategia intermedia, se ha sostenido (interpretando el mismo Estatuto de Roma) que la lesión a la humanidad en la comisión de un crimen internacional se traduce en que el hecho interesa a la comunidad universal, debido a la gravedad del mismo y a la incapacidad de sistemas judiciales domésticos de enfrentarlo ${ }^{45}$.

Este es el primer vínculo dogmático que se puede establecer entre el derecho penal internacional y los derechos humanos. Como se aprecia, dependiendo del rendimiento doctrinario de la categoría "humanidad", el esfuerzo de legitimación del derecho penal internacional en atención a los intereses protegidos puede aspirar a desembarazarse del discurso de los derechos humanos individuales. Esta autonomía discursiva es la que exigen autores como Robinson, en atención a que la lógica del discurso del derecho internacional de derechos humanos es puramente prospectiva, y desatiende la dimensión retrospectiva del derecho punitivo, que se expresa en los requisitos legitimatorios de agencia intencional y culpabilidad ${ }^{46}$.

Existe una segunda dimensión en la que se relacionan ambos sistemas, que es de orden pragmático. Fuera de problemas de legitimación, el establecimiento de normas de derechos humanos puede fundar deberes de establecimiento de normas punitivas

43 WERLE, 2014: 27-28, con referencias ulteriores.

44 Uno de los esfuerzos más notables en esta dirección es el de LuBAN, David (2004). "A Theory of Crimes Against Humanity". The Yale Journal of International Law 29: 85-167. Esta estrategia individualiza el carácter colectivo de la categoría "humanidad", de modo que tiene el potencial de asimilarla al atributo de la dignidad. Así, por ejemplo, Nicolás Carrillo reemplaza a la humanidad con la dignidad humana, la que, junto a la protección de la paz y la seguridad, constituyen genuinos bienes jurídicos globales [global legal goods], cuyas fuentes de protección no son solo los catálogos de derechos, sino también las garantías del derecho humanitario y las normas de derecho penal internacional. CARRILlo, Nicolás (2013). "The protection of global legal goods". Anuario Mexicano de Derecho Internacional XIII: 424-425. Para un análisis de la dignidad humana como objeto de protección del derecho penal doméstico, incluyendo una taxonomía de delitos (que no incluyen crímenes internacionales) y una breve discusión de la posibilidad de objetivar el valor en cuestión, véase Hörnle, Tatjana y Mordechai Kremnitzer (2011). "Human dignity as a protected interest in criminal law". Israel Law Review 44: 143-167.

45 Así Schabas, William (2011). An introduction to the International Criminal Court. 4th Edition. Cambridge: Cambridge University Press, p. 90.

46 Robinson, 2008: 947. 
Javier Gallego Saade y Juan Francisco Lobo

La jurisdicción universal de protección de derechos fundamentales en la jurisprudencia chilena (comentario al fallo de la Corte Suprema Rol N¹7.393-2015)

internacionales. Como lo señala el mismo Robinson, la necesidad estricta de configurar un deber de punición a partir de la consagración de un deber de protección (humanitario o de derechos humanos) ha sido defendida irreflexivamente por la doctrina especializada $^{47}$. Es decir, se ha asumido que todo lo que protege el derecho humanitario o los derechos humanos debe ser criminalizado.

Esta correlación de deberes ha sido asumida por la jurisprudencia internacional. El Tribunal Europeo de Derechos Humanos, en Pretty v. United Kingdom, no solo negó la existencia de un derecho a morir, sino que afirmó que la protección del derecho a la vida "debe extenderse más allá del deber primario de aseguramiento [del derecho] y debe incluir la implementación de disposiciones efectivas de derecho penal para prevenir la comisión de actos lesivos contra la persona (...)"48. Por cierto, sin perjuicio de que la correlación se pueda construir en la dimensión internacional, el origen de esta se encuentra en el derecho doméstico. Fue formulada por primera vez por el Tribunal Constitucional Federal alemán, en su célebre fallo de control abstracto de constitucionalidad relativo a la regulación del aborto consentido (BVerfGE 39, 1). Allí el Tribunal estableció que el deber constitucional de proteger la vida del que está por nacer se extendía como mandato dirigido al legislador de dispensar protección penal de modo de asegurar dicho derecho a la vida.

En la dimensión doméstica, como ya se aprecia, la fundamentación de un deber de punición a partir de un deber de protección tiene como parámetro la Constitución, y por esa razón fue planteada por primera vez por un Tribunal Constitucional. Esto implica que el deber de punición puede ser interpretado como una concreción del mandato constitucional dirigido al legislador de proteger derechos fundamentales ${ }^{49}$. El correlato negativo de ello es la pérdida de autonomía que sufre el legislador, en el ejercicio de su prerrogativa de punición. Este es el aspecto problemático que está ausente en la dimensión internacional. En este plano no hay tal cosa como un parámetro normativo de distribución de competencias, ni tampoco un órgano legislador que reclame autonomía, de modo que la necesidad de establecimiento de deberes de punición a partir de deberes de protección solo puede presentarse como parte de una reconstrucción doctrinaria, pues carece de desempeño institucional.

En definitiva, los dos vínculos que se han planteado presuponen sistemas, en principio, diferenciados; y en cada caso hay costos que asumir. En el primer caso se retrocede a formas poco sofisticadas de legitimación racional del derecho punitivo, y se priva a la legislación punitiva de fundamento autónomo; y en el segundo caso se sacrifica la autonomía competencial del legislador punitivo. Por cierto, ninguno de estos costos es asumido por la Corte al presentar conjuntamente un tratado punitivo con un tratado de derechos humanos.

47 Robinson, 2008: nota 129.

48 Tribunal Europeo de Derechos Humanos. Caso Pretty v. United Kingdom. Sentencia de 29 de abril de 2002. Nr. 2346/02 párrafo 38.

49 Fundamental Viganò, Francesco (2014). "La Arbitrariedad del No Punir. Sobre las Obligaciones de Tutela Penal de los Derechos Fundamentales". Política Criminal 9(18): 428-476. 


\section{Conclusión}

El fallo de la Corte invoca una práctica que denomina jurisdicción universal de protección de derechos fundamentales. Se trata de una invención de la Corte. Para permitirle algún desempeño a su invención, la Corte desconoce la regulación vigente de las instituciones que invoca. Debe hacerlo, pues invoca sistemas estructuralmente diferenciados. Así, desconoce el rol que juega la Convención Americana en la coordinación de intereses de Estados miembros en torno al respeto de derechos humanos, en la medida en que dispone de una categoría de derecho doméstico (los derechos constitucionales) para manifestar una expectativa de reforzamiento de derechos fundamentales de ciudadanos venezolanos, a la luz de actos que tienen lugar en territorio venezolano. Justifica su decisión apelando a la práctica histórica de jurisdicción punitiva universal por crímenes internacionales, invocando instrumentos normativos internacionales y jurisprudencia comparada, sin detenerse a analizar si efectivamente dan cuenta de la práctica de que se trata. Este razonamiento la lleva, por último, a asimilar irreflexivamente el derecho punitivo y los derechos fundamentales.

En la conclusión de este artículo, sin embargo, se ofrecerá una interpretación caritativa del fallo. El punto de partida se encuentra en la asunción de que, en algún nivel, tanto el derecho penal internacional como el derecho internacional de los derechos humanos se orientan a la protección de intereses comunes de toda la humanidad y son, entonces, funcionales a la conformación de una comunidad internacional.

Bajo cierta interpretación posible del fallo, la decisión se explica como una anticipación de la conformación de una comunidad internacional latinoamericana, cuyos miembros se coordinan disponiendo de estándares comunes. La Corte de hecho es explícita en que la jurisdicción extraterritorial no mediada por factores de conexión ni tratados internacionales se justifica en "casos de singular importancia y trascendencia para la pervivencia de la propia comunidad internacional" (considerando tercero). En una interpretación caritativa de dicha expresión, el desprecio que la Corte ha mostrado por la soberanía estatal se explica porque anticipa una convivencia regional en condiciones de postsoberanía, como la que caracteriza a la comunidad europea ${ }^{50}$.

Lo cierto es que la conformación de una comunidad internacional, coordinada y situada regionalmente, es un proceso que implica asentar instituciones jurídicas, a la vez que resolver diferencias políticas. El asentamiento del sistema jurídico internacional exige compromiso institucional por parte de los Estados con los mecanismos de resolución de controversias dispuestos en los cuerpos normativos internacionales, lo que implica disponer de ellos como mediadores en el proceso de coordinación. En ese sentido la jurisdicción universal es problemática, pues supone que el Estado cuyo Poder Judicial la ejerce se arroga la representación de toda la comunidad universal y la aptitud para proteger los intereses de la humanidad ${ }^{51}$. Esto explica que hasta hoy la relación entre la práctica de la jurisdicción (punitiva) universal y la jurisdicción internacional de un

50 Mac Cormick, Neil (2002). Questioning Sovereignty. Law, State and Nation in the European Commonwealth. Oxford: Oxford University Press, pp. 123-136.

51 Sobre la doble dimensión de la jurisdicción universal, como protección de la humanidad y como ejercicio de violencia MAnN, Itamar (2010). "The Dual Foundation of Universal Jurisdiction: Towards a Jurisprudence for the 'Court of Critique”'. Transnational Legal Theory 1(4): 485-521. 
Javier Gallego Saade y Juan Francisco Lobo

La jurisdicción universal de protección de derechos fundamentales en la jurisprudencia chilena (comentario al fallo de la Corte Suprema Rol N¹7.393-2015)

tribunal penal permanente como la Corte Penal Internacional no sea una relación del todo resuelta, y haya quienes aboguen por transferir la una a la otra ${ }^{52}$. Ello revela una diferencia crucial entre el derecho penal internacional y los derechos humanos: mientras que los segundos se desempeñan en un sistema asentado, la comunidad universal sigue hasta hoy expectante frente a la evolución del primero, y la jurisdicción universal ha jugado un rol importante en esa incertidumbre. Si bien existe un proyecto antropocéntrico común a estas dos ramas del derecho internacional público, de manera tal que ambas han contribuido a perfilar al individuo como un nuevo sujeto normativo de este sistema jurídico durante los últimos 70 años, lo cierto es que dichas ramas se refieren a dimensiones diferentes, aunque complementarias, de la personalidad jurídica internacional. Dicha personalidad se define en función de dos cualidades copulativas: (i) la capacidad de ser titular de derechos y de presentar reclamaciones ante instancias jurisdiccionales para defenderlos (la "dimensión de derechos"); y (ii) la condición de ser destinatario de deberes jurídicos y de poder ser hecho responsable internacionalmente por su infracción (la "dimensión de deberes") ${ }^{53}$. A partir de 1945 se ha intentado extender ambas dimensiones de la personalidad jurídica internacional, más allá de los Estados, a los individuos ${ }^{54}$, en la forma de los derechos humanos (dimensión de derechos) y del derecho penal internacional ${ }^{55}$ (dimensión de deberes reforzados punitivamente, que han sido filosóficamente caracterizados como verdaderos "deberes humanos") ${ }^{56}$.

De este modo, la decisión de la Corte, aun en caso de estar inspirada en un afán de integración y conformación de una genuina comunidad internacional, puede estar dando un paso en falso al trasladar la jurisdicción punitiva universal hacia el ámbito de la protección de derechos fundamentales universales, acentuando el ya exacerbado protagonismo de la dimensión de titularidad de derechos humanos de que gozan los individuos, en desmedro del desarrollo de la dimensión referida a los "deberes humanos" de comportamiento reforzados punitivamente que tiene todo ser humano para con sus congéneres.

\section{Bibliografía}

Aguilar, Gonzalo (2006). "El Principio de Jurisdicción Universal: Una Propuesta de Aplicación en Chile”. Estudios Constitucionales 4(1): 333-366.

Ambos, Kai (2013). Derecho Penal y Procesal Penal Internacional y Europeo. Nuevos Ensayos. Santiago: Legal Publishing-Thomson Reuters.

BAssiouni, M. Cherif (2001). "Universal Jurisdiction for International Crimes: Historical Perspectives and Contemporary Practice". Virginia Journal of International Law 42(1): 82-162.

52 Hoover, Dalila (2011). "Universal Jurisdiction not so Universal: A Time to Delegate to the International Criminal Court”, Cornell Law School Inter-University Graduate Student Conference Papers, 6-4.

53 BRownlie, 2012: 115.

54 Una mirada crítica de este proceso y del éxito de su pretensión puede encontrarse en CRAWFORD, James (2014). Chance, Order, Change: The Course of International Law. La Haya: The Hague Academy of International Law, p. 210.

55 BRownlie, 2012: 126.

56 HöfFe, Otfried (2008). El proyecto político de la modernidad. Buenos Aires: FCE, p. 141. 
Brownlie, Ian (2012). Principles of Public International Law. Edited by James Crawford. $8^{\text {th }}$ Edition. Oxford: Oxford University Press.

CarRiLlo, Nicolás (2013). "The protection of global legal goods". Anuario Mexicano de Derecho Internacional XIII: 405-450.

Cassese, Antonio et al. (2013). International Criminal Law. 3rd Edition. Oxford: Oxford University Press.

Crawford, James (2014). Chance, Order, Change: The Course of International Law. La Haya: The Hague Academy of International Law.

Dulitzky, Ariel (2015). "An Inter-American Constitutional Court? The Invention of the Conventionality Control by the Inter-American Court of Human Rights". Texas International Law Journal 50(1): 45-93.

Ferrada, Juan Carlos, Andrés Bordalí y Kamel Cazor (2003). "El recurso de protección como mecanismo de control jurisdiccional ordinario de los actos administrativos: una respuesta inapropiada a un problema jurídico complejo". Revista de Derecho XIV: $67-81$.

Fuentes, Ximena (2004). "La Jurisdicción Universal y la Corte Penal Internacional". Revista de Estudios de la Justicia 4: 123-134.

Gardbaum, Stephen (2008). "Human Rights as International Constitutional Rights". European Journal of International Law 19(4): 749-768.

Gómez, Antonio (2003). El Ius Cogens Internacional. Estudio histórico-crítico. México D.F.: UNAM.

Higgins, Rosalyn (2010). Problems and Process. International Law and How We Use it. Oxford: Clarendon Press.

Hoover, Dalila (2011). "Universal Jurisdiction not so Universal: A Time to Delegate to the International Criminal Court", Cornell Law School Inter-University Graduate Student Conference Papers, 6-4.

Höfre, Otfried (2008). El proyecto político de la modernidad. Buenos Aires: FCE.

HörnLe,Tatjana y Mordechai Kremnitzer (2011). "Human dignity as a protected interest in criminal law". Israel Law Review44: 143-167.

LANGer, Máximo (2011). "The diplomacy of universal jurisdiction: The political branches and the transnational prosecution of international crimes". American Journal of International Law 105(1): 1-49.

Luban, David (2004). "A Theory of Crimes Against Humanity". The Yale Journal of International Law 29: 85-167.

Mac Cormick, Neil (2002). Questioning Sovereignty. Law, State and Nation in the European Commonwealth. Oxford: Oxford University Press.

Mann, Itamar (2010). "The Dual Foundation of Universal Jurisdiction: Towards a Jurisprudence for the "Court of Critique". Transnational Legal Theory 1(4): 485-521. 
Javier Gallego Saade y Juan Francisco Lobo

La jurisdicción universal de protección de derechos fundamentales en la jurisprudencia chilena (comentario al fallo de la

Corte Suprema Rol N¹7.393-2015)

Murphy, Sean (2012). Principles of International Law. $2^{\text {nd }}$ Edition. Michigan: Thomson Reuters.

Macedo, Stephen (ed.) (2001). The Princeton Principles on Universal Jurisdiction. Princeton: Princeton University.

OchoA, María Julia (2014). "La protección de los derechos humanos en Venezuela frente a la denuncia de la Convención Americana sobre Derechos Humanos". Revista Latinoamericana de Derechos Humanos 25(1): 195-211.

Ríos, Lautaro (2007). "La Acción Constitucional de Protección en el Ordenamiento Jurídico Chileno". Estudios Constitucionales 5(2): 37-60.

Robinson, Darryl (2008). "The identity crisis of International Criminal Law". Leiden Journal of International Law 21: 925-963.

SAfFerling, Christoph (2004). "Can Criminal Prosecutions be the Answer to Massive Human Rights Violations?”.German Law Journal 5(12): 1469-1488.

Schabas, William (2011). An introduction to the International Criminal Court. 4th Edition. Cambridge: Cambridge University Press.

SchünEmann, Bernd (2007). "El principio de protección de bienes jurídicos como punto de fuga de los límites constitucionales de los tipos penales y de su interpretación”, en La Teoría del Bien Jurídico (editor: Hefendehl, Ronald), Madrid: Marcial Pons.

SMeUlers, Alette y Fred GrüNFeld (2011). International Crimes and other Gross Human Rights Violations. Leiden and Boston: Martinus Nijhoff Publishers.

Viganò, Francesco (2014). "La Arbitrariedad del No Punir. Sobre las Obligaciones de Tutela Penal de los Derechos Fundamentales”. Política Criminal 9(18): 428-476.

Villarino, Cristina (2006). "The Crime of Aggression before the House of Lords”. Journal of International Criminal Justice 4: 866-877.

WerLe, Gerhard (2014). Principles of International Criminal Law. 3rd Edition. Oxford: Oxford University Press.

\section{Tratados InTERnacionales}

Organización de las Naciones Unidas. Convención para la Prevención y Sanción del Delito de Genocidio, adoptada el 9 de diciembre de 1948.

Convenios de Ginebra I, II, III y IV, adoptados el 12 de agosto de 1949.

Convención de Viena sobre el Derecho de los Tratados, adoptada el 23 de mayo de 1969, art. 53.

Protocolo Adicional I a los Convenios de Ginebra, adoptado el 10 de junio de 1977.

Convención contra la tortura y otros tratos crueles, inhumanos y degradantes, adoptada el 10 de diciembre de 1984.

Organización de los Estados Americanos. Convención Americana de Derechos Humanos, adoptada el 22 de noviembre de 1969.

Estatuto de Roma de la Corte Penal Internacional, adoptado el 17 de junio de 1998.

$\cdot 150$ 


\section{JURISPRUDENCIA}

Conte IDH. Caso Almonacid Arellano y otros vs. Chile (excepciones preliminares, fondo, reparaciones y costas). Sentencia de 26 de septiembre de 2006. Serie C N 154 .

Caso Trabajadores Cesados del Congreso (Aguado Alfaro y otros) vs. Perú (excepciones preliminares, fondo, reparaciones y costas). Sentencia de 24 de noviembre de 2006. Serie $\mathrm{C} \mathrm{N}^{\circ} 158$.

Caso Cabrera García y Montiel Flores vs. México (excepciones preliminares, fondo, reparaciones y costas). Sentencia de 26 de noviembre de 2010. Serie $\mathrm{C} \mathrm{N}^{\circ} 220$.

Caso Gelman vs. Uruguay (fondo y reparaciones). Sentencia de 24 de febrero de 2011. Serie C No221.

Caso Atala Riffo y Niñas vs. Chile (excepciones preliminares, fondo, reparaciones y costas). Sentencia de 24 de febrero de 2012. Serie C No 239.

Corte Internacional de Justicia. República Democrática del Congo v. Bélgica (Arrest Warrant). Fondo. Sentencia de 14 de febrero de 2002. Serie 837.

Nicaragua v. Estados Unidos (Actividades Militares y Paramilitares en y contra Nicaragua). Fondo. Sentencia de 27 de junio de 1986. Serie 520.

República Democrática del Congo v. Ruanda. Fondo. Sentencia de 3 de febrero de 2006. Serie 126.

Tribunal Constitucional Chileno. Fallo Rol 346. 8 de abril de 2002 (control de constitucionalidad del Estatuto de Roma).

Tribunal Europeo de Derechos Humanos. Caso Pretty v. United Kingdom. Sentencia de 29 de abril de 2002. Nr. 2346/02.

Recibido: 15 de marzo de 2016

Aceptado: 1 de junio de 2016 